\title{
ВИКОРИСТАННЯ РІШЕНЬ ОБЕРНЕНОЇ ЗАДАЧІ ЛІНІЙНИХ ПРОЦЕСІВ АВТОРЕГРЕСІЇ ДЛЯ ПОБУДОВИ СИСТЕМ ВІБРОДІАГНОСТИКИ ВУЗЛІВ ГЕНЕРАТОРІВ ВІТРОУСТАНОВОК
}

\section{В.М. Зварич, докт. техн. наук}

Інститут електродинаміки НАН України, 03680, м. Київ, пр.-т Перемоги 56

Інститут відновлюваної енергетики НАН України, 02094, м. Київ, вул. Гната Хаткевича, 20A

В роботі розглянуто деякі методи діагностування технічного стану енергетичного обладнання. Наведено порівняння різних методів вібродіагностики, щчо можуть бути використані при діагностуванні технічного стану генераторів вітроустановок. Розглянуто використання лінійних випадкових проиесів для побудови систем діагностики генераторів вітроустановок. Представлено метод знаходження характеристичної функиї̈ породжуючого прочесу для лінійного процесу авторегресії другого порядку AR(2), щьо має Гамма-розподіл. Властивості Пуасонівських спектрів стрибків використовуються для рішення такої проблеми. Вирішення такої задачі, базується на властивості характеристичної функиії стаціонарного лінійного випадкового процесу авторегресії $A R(2), \xi_{t}+a_{1} \xi_{t-1}+a_{2} \xi_{t-2}=\varsigma_{t}, t \in Z$, де $\left\{a_{1}, a_{2} \neq 0\right\}$ nараметри авторегресії; $\mathrm{Z}=\{\ldots,-1,0,1, \ldots\}$ множина ціллих чисел; $\left\{\zeta_{t}, t \in \mathrm{Z}\right\}$ випадковий процес з дискретним часом та незалежними значеннями, щэо має безмежно подільний закон розподілу, який часто називають породжуючим прочесом. Іноді таку задачу називають оберненою задачею. В статті відзначається щзо одновимірний логарифм характеристичної функиії лінійного стаціонарного прочесу авторегресії можна задати одновимірною характеристичною функиією в канонічному представленні Колмогорова, $\ln f_{\xi}(u, t)=\ln f_{\xi}(u, 1)=i m_{\xi} u+\int_{-\infty}^{\infty}\left\{e^{i u x}-1-i u x\right\} \frac{d K_{\xi}(x)}{x^{2}}$, де параметр $m_{\xi}$ та спектральна функиія стрибків $K_{\xi}(x)$ однозначно визначають характеристичну функиію. Логарифм характеристичної функиії лінійного стаціонарного процесу авторегресії може бути також записана в такій формі:

$\ln f_{\xi}(u, t)=\ln f_{\xi}(u, t)=\operatorname{im}_{\zeta} u \sum_{\tau=-\infty}^{\infty} \phi(\tau)+\sum_{\tau=-\infty}^{\infty} \int_{-\infty}^{\infty}\left(e^{i u x \phi(\tau)}-1-i u x \phi(\tau)\right) \frac{d K_{\zeta}(x)}{x^{2}}$, де параметри $m_{\varsigma}$ та $K_{\zeta}(x)$ визначають характеристичну функиію породжуючого процесу $\varsigma_{t}$ a $\phi(\tau)$ єядром лінійного випадкового прочесу $\xi_{t}$. Параметри $m_{\xi}$ та $m_{\varsigma}$, та пуасонівського спектру стрибків $K_{\xi}(x) \quad K_{\zeta}(x)$ взаємоповязані наступним чином $m_{\xi}=m_{\zeta} \sum_{\tau=0}^{\infty} \phi(\tau)$, $K_{\xi}(x)=\int_{-\infty}^{\infty} R_{\phi}(x, y) d K_{\varsigma}(y) . \quad R_{\phi}(x, y)$ є ядром перетворення яке є інваріантним до породжуючого $\varsigma_{t} i$ визначається за допомогою коефіцієнтів $\left\{a_{1}, a_{2} \neq 0\right\}$. Властивості $R_{\phi}(x, y)$ використовуються для вирішення оберненої задачі. Показано приклад знаходження пуасонівських спектрів стрибків і характеристичної функиії для лінійного процесу авторегресії другого порядку, що має Гамма-розподіл.

Метод може бути використаний для вирішення оберненої задачі для авторегресійних процесів інших класів. Показано використання отриманих результатів для моделювання вібраційних сигналів генератора вітроустановки. Бібл. 17, рис. 5

Ключові слова: лінійний прочес авторегресії, характеристична функиія, ядро перетворення, породжуючий прочес, безмежно-подільний закон розподілу, Гамма -розподіл, вібродіагностика генераторів вітроустановок.

\section{USE OF SOLUTIONS OF THE REVERSE PROBLEM OF LINEAR AUTOREGRESSION PROCESSES FOR SIMULATION OF VIBRATION SIGNALS OF ROTATING NODES OF WIND GENERATORS}

\author{
V. Zvarich, doctor of technical science \\ Institute of electrodynamics of the National Academy of Sciences of Ukraine \\ 03680, 56 Peremohy av., Kyiv, Ukraine \\ Institute of Renewable Energy of the National Academy of Sciences of Ukraine \\ 02094, 20A Hnata Khotkevycha Str., Kyiv, Ukraine
}

Difference methods of power equipment diagnostics are discussed. Comparison of different vibration methods for wind generator diagnostic is represented. Linear autoregressive processes for construction of wind generator expert systems is considered. Poisson jump spectra's properties are used for the solution of the problem. A method of Gammal AR(2) generative process characteristic function determination is discussed. The method is suggested for definition the characteristic function for linear autoregressive $A R(2)$ processes with Gamma distribution of the generative process $\left\{\zeta_{t}, t \in Z\right\}$, namely, autoregressive process AR(2) 
$\xi_{t}+a_{1} \xi_{t-1}+a_{2} \xi_{t-2}=\varsigma_{t}, \quad t \in Z$, where $\left\{a_{1}, a_{2} \neq 0\right\}$ are autoregressive parameters; $Z=\{\ldots,-1,0,1, \ldots\}$ is a set of integers; $\left\{\zeta_{t}, t \in \mathrm{Z}\right\}$ is the random process with discrete time and independent values having an infinitely divisible distribution, the process is often called the generating process. Sometimes the problem is called inverse problem. It is noted that the logarithm of the onedimensional characteristic function of the linear stationary autoregressive process may be determined in Kolmogorov canonical representation $\ln f_{\xi}(u, t)=\ln f_{\xi}(u, 1)=i m_{\xi} u+\int_{-\infty}^{\infty}\left\{e^{i u x}-1-i u x\right\} \frac{d K_{\xi}(x)}{x^{2}}$, in which the parameter $m_{\xi}$ and spectral functions of jumps $K_{\xi}(x)$ define unequivocally the characteristic function. The logarithm of the characteristic function of the linear stationary autoregressive process may be written down also in the following form $\ln f_{\xi}(u, t)=\ln f_{\xi}(u, t)=i m_{\zeta} u \sum_{\tau=-\infty}^{\infty} \phi(\tau)+\sum_{\tau=-\infty}^{\infty} \int_{-\infty}^{\infty}\left(e^{i u x \phi(\tau)}-1-i u x \phi(\tau)\right) \frac{d K_{\zeta}(x)}{x^{2}}$ where the parameters $m_{\varsigma}$ and $K_{\zeta}(x)$ define the characteristic function of the generative process $\varsigma_{t}$ while $\phi(\tau)$ is the kernel of the linear random process $\xi_{t}$. The parameters $m_{\xi}$ and $m_{\zeta}$, and Poisson spectra of jumps $K_{\xi}(x) \quad K_{\varsigma}(x)$ are interrelated as follows $m_{\xi}=m_{\zeta} \sum_{\tau=0}^{\infty} \phi(\tau), \quad K_{\xi}(x)=\int_{-\infty}^{\infty} R_{\phi}(x, y) d K_{\zeta}(y)$ where $R_{\phi}(x, y)$ is so-called transform kernel, which is invariant with generative process $\varsigma_{t}$ and uniquely defined by the coefficients $\left\{a_{1}, a_{2} \neq 0\right\}$. Properties of $R_{\phi}(x, y)$ are used for the inverse problem solution. Examples the peculiar features of determination of Poisson spectra of jump and characteristic function for the autoregressive AR(2) process are considered. Logarithm of characteristic function for linear AR(2) process with Gamma distribution was calculate.

The method may be used for a solution of the reversible problem for AR processes of others classes. An example of application of vibration signal simulation of wind power generator is considered. Ref. 17, fig. 5.

Keywords: linear processes of autoregression, characteristic function, kernel of transformation, generative process, infinitely divisible law of distribution, Gamma-distribution, vibrodiagnosis of rolling bearings.

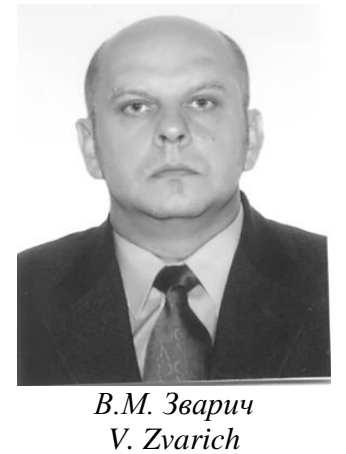

Відомості про автора: докт. техн. наук., стар.наук.співр. Інституту відновлюваної енергетки НАН України, пров. наук. співр. Інституту електродинаміки НАН України. Освіта: Національний технічний університет України «Київський політехнічний інститут» радіотехнічний факультет за спеціальністю «Радіотехніка».

Наукова сфера: відновлювана енергетика, обробка сигналів, експертні системи.

Публікації: 100, в тому числі 1 патент

ORCID: 0000-0002-1271-4954

Контакти: тел.: +38 0442396534

e-mail: zvaritch@nas.gov.ua
Author information: doctor of technical science, senior researcher of Renewable Energy Institute of NAS of Ukraine, leading researcher of Institute of electrodynamics of the NAS of Ukraine.

Education: National Technical University of Ukraine "Kyiv Polytechnic Institute" Radioengineering Faculty by specialty "Radioengineering".

Reasearch area: renewable energy, signal processing, expert systems.

Publications: 100 including 1 patent

Contacts: tel.: +38 0442396534

e-mail: zvaritch@nas.gov.ua

\section{Перелік використаних позначень та скорочень:}

a - параметри авторегресії;

p - порядок авторегресії;

Z - множина цілих чисел;

$t$ - час;

$m_{\xi}$ - параметр, що визначає характеристичну функцію спостережуваного процесу $\xi_{t}$;

$m_{\varsigma}$ - параметр, що визначає характеристичну функцію породжуючого процесу $\varsigma_{t}$;

$K_{\xi}(x)$ - спектральна функція стрибків в формулі А. Н. Колмогорова однозначно визначаюча характеристичесну функцію спостережуваного процесу $\xi_{t}$;

$K_{\zeta}(x)$-спектральна функція стрибків в формулі А.Н. Колмогорова однозначно визначаюча характеристичну функцію породжуючого процесу $\varsigma_{t}$;

$R_{\phi}(x, y)$ - ядро перетворення;

$U[$.$] \quad - функція Хевісайда;$ b -параметр характеристичної функції Гамма розподілу;

$f_{\xi}(u, t)$ - характеристична функція спостережуваного процесу $\xi_{t}$;

$f_{\varsigma}(u, t)$ - характеристична функція породжуючого процесу $\varsigma_{t}$;

$r(t, n)$ - кореляційна функція процесса $\xi_{t}$;

$i \quad$ - знак уявної одиниці;

$M[$.$] \quad - знак математичного сподівання.$

Букви грецького алфавіту:

$\xi_{t} \quad$ - спостережуваний випадковий процес;

$\varsigma_{t} \quad$ - породжуючий випадковий процес;

$\phi(\tau) \quad$ - ядро лінійного випадкового процесу $\xi_{t}$;

$\theta$ - параметр характеристичної функції Гамма розподілу. 
Вступ. Включення сучасних систем діагностування до складу вітроенергетичних установок може істотно підвищити надійність їх функціонування [13].

Системи технічної діагностики енергетичного обладнання досить різноманітні і базуються на різних методах (рис.1). Це - тепловий контроль i діагностика, контроль технічного стану на основі аналізу електричних і магнітних полів, вібродіагностика, акустична діагностика, діагностика на основі методів акустичної емісії тощо.

Відзначимо, що допуски на зміну величини струму і температури досить великі і суттєво перевищують ті зміни, які виникають при появі різних потенційно небезпечних дефектів, особливо на ранніх стадіях їх виявлення. Показники надійності роботи енергообладнання визначаються результатом спільного впливу як факторів, що визначають умови експлуатації, так і внутрішніх чинників, які описують властивості енергетичного обладнання. Поєднання таких факторів носить випадковий характер, тому застосування статистичних методів для вирішення таких завдань діагностування доцільно у багатьох практичних випадках.

Системи технічної діагностики крупного енергетичного обладнання

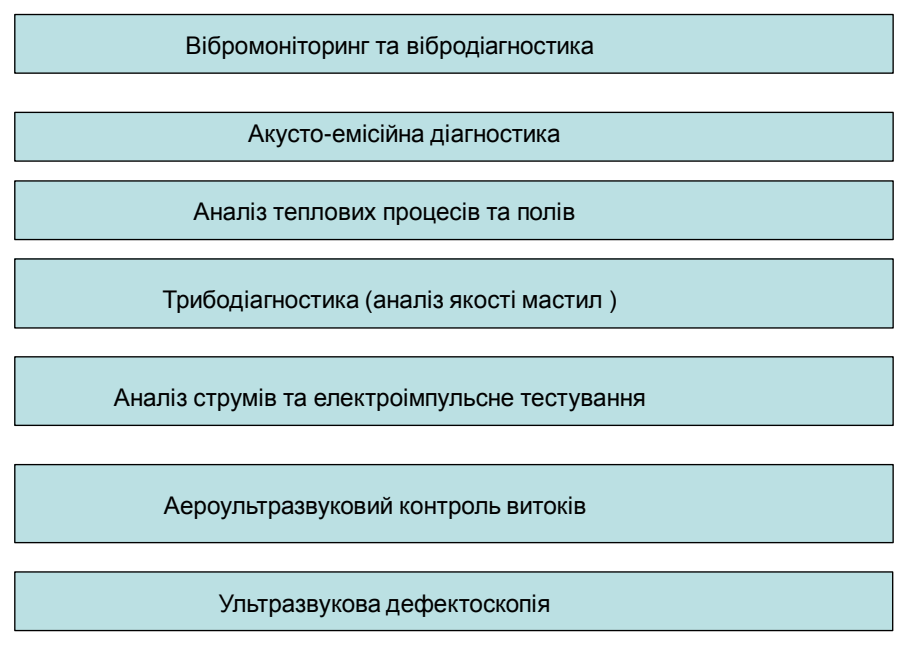

Рис. 1. Методи вібродіагностики енергетичного обладнання.

Fig. 1. Power equipment diagnosis methods.

Найбільш перспективними методами контролю і діагностики $\epsilon$ неруйнівні методи, які зазвичай, реалізуються за допомогою спеціалізованих комп'ютерних систем.

Одними 3 найбільш перспективних систем діагностування обладнання є системи вібродіагностики, що дають можливість визначити дефекти на ранніх стадіях їх появи $[1,6]$.

Рішення завдання побудови ефективної системи діагностування генераторів вітроустановки при використанні такого підходу проводять в декілька етапів:

Перший з них - побудова математичної моделі діагностичних сигналів.

Другий етап передбачає створення і вибір відповідного програмно-технічного забезпечення, на базі якого реалізовувалися ці системи.

Третій етап - розробка методів побудови вирішальних правил по діагностиці генераторів вітроустановки.
Необхідно також провести перевірку працездатності запропонованих методів.

На рис. 2 наведені деякі порівняльні характеристики основних методів вібродіагностики і запропонованого методу вібродіагностики, заснованого на використанні лінійних процесів авторегресії. На відміну від інших, запропонований метод авторегресії допускає аналіз вібросигналів в широкій смузі частот, працездатний при низьких частотах обертання, застосовується для негаусових безмежно-подільних розподілів діагностичних ознак або діагностичних сигналів.

Відзначимо, що, наприклад система вібродіагностики генераторів вітроустановки фірми Bently Nevada використовує в своєму складі платформу прикладних програм, розроблену спільно 3 компанією General Electric, і використовує для вібродіагностики метод обвідної. 


\begin{tabular}{|c|c|c|c|c|c|}
\hline Назва методу & $\begin{array}{l}\text { Швид- } \\
\text { кість, } \\
\text { об/хв }\end{array}$ & $\begin{array}{l}\text { стето- } \\
\text { скоп }\end{array}$ & Переваги & Недоліки & Особливості \\
\hline Метод обвідної & $\begin{array}{l}>600 \\
\text { об/хв }\end{array}$ & $\begin{array}{l}\text { Не } \\
\text { обов'яз- } \\
\text { ково }\end{array}$ & $\begin{array}{l}\text { Достатньо простий } \\
\text { в реалізації, якщо } \\
\text { відомі власні } \\
\text { частоти об'єкту } \\
\text { діагностування }\end{array}$ & $\begin{array}{l}\text { Для эфектив- } \\
\text { ного результату } \\
\text { необхідна } \\
\text { вибірка 50-100 } \\
\text { обертів }\end{array}$ & $\begin{array}{l}\text { Має сенс для } \\
\text { вузькосмуго- } \\
\text { вого } \\
\text { гаусового } \\
\text { процесу }\end{array}$ \\
\hline $\begin{array}{c}\text { Спектральній } \\
\text { аналіз }\end{array}$ & $\begin{array}{l}\text { Різно- } \\
\text { манітна }\end{array}$ & $\begin{array}{l}\text { Доціль- } \\
\text { но }\end{array}$ & $\begin{array}{l}\text { Достатньо добре } \\
\text { розроблений }\end{array}$ & $\begin{array}{l}\text { Можна } \\
\text { використати не } \\
\text { для всіх видів } \\
\text { машин та типів } \\
\text { дефректів }\end{array}$ & $\begin{array}{l}\text { Широко } \\
\text { використовує } \\
\text { ться БПФ }\end{array}$ \\
\hline $\begin{array}{l}\text { Метод ударних } \\
\text { імпульсів }\end{array}$ & $\begin{array}{l}>2000 \\
\text { об/хв }\end{array}$ & $\begin{array}{l}\text { Доціль- } \\
\text { но }\end{array}$ & $\begin{array}{l}\text { Хороші результати } \\
\text { для високо- } \\
\text { обертових машин }\end{array}$ & $\begin{array}{l}\text { Непридатний } \\
\text { для низко- } \\
\text { оберотных } \\
\text { машин }\end{array}$ & $\begin{array}{l}\text { Рабоча } \\
\text { частота } \\
32 \text { кГц }\end{array}$ \\
\hline $\begin{array}{c}\text { Статистичний } \\
\text { спектральний } \\
\text { аналіз }\end{array}$ & $\begin{array}{l}\text { Різном } \\
\text { анітна }\end{array}$ & $\begin{array}{l}\text { Не } \\
\text { обов'яз- } \\
\text { ково }\end{array}$ & $\begin{array}{c}\text { Застосовується для } \\
\text { високообертових і } \\
\text { низькообертових } \\
\text { машин }\end{array}$ & $\begin{array}{l}\text { Необхідно } \\
\text { зробити вибір } \\
\text { оптимального } \\
\text { сгладжувально- } \\
\text { го вікна }\end{array}$ & $\begin{array}{l}\text { Роздільна } \\
\text { здатність } \\
1 /(\Delta t \times n), n- \\
\text { число відлі- } \\
\text { ків АКФ }\end{array}$ \\
\hline $\begin{array}{l}\text { Авторегресійний } \\
\text { аналіз }\end{array}$ & $\begin{array}{l}>3 \\
\text { об/xв }\end{array}$ & $\begin{array}{l}\text { Не } \\
\text { обов'яз- } \\
\text { ково }\end{array}$ & $\begin{array}{l}\text { Рекурентні алго- } \\
\text { ритми оцінки пара- } \\
\text { метрів і порядка } \\
\text { авторегресії }\end{array}$ & $\begin{array}{l}\text { Фіксація частот } \\
\text { квантування та } \\
\text { фільтрації } \\
\text { вібросигналу }\end{array}$ & $\begin{array}{l}\text { P -порядок } \\
\text { AR; Р+1 чи- } \\
\text { сло відліків } \\
\text { АКФ }\end{array}$ \\
\hline
\end{tabular}

Рис. 2. Порівняльні характеристики методів вібродіагностики.

Fig. 2. Comparative characteristics of diagnostic methods.

Постановка задачі. У даній роботі для вирішення завдань діагностики енергетичного обладнання пропонується використовувати методи авторегресії, засновані на застосуванні лінійних процесів авторегресії для моделювання, зокрема, діагностичних сигналів, що виникають при роботі генераторів вітроустановок. Базуються такі моделі на різницевих рівняннях $[1,2,7,16,17]$.

Доцільність такого підходу полягає в наступному. Сучасні системи моніторингу, контролю та діагностики, як правило, в своєму складі містять контролер, мікро-ЕОМ, ПК або промисловий комп'ютер i, отже АЦП. Тобто проводиться обробка дискретних сигналів. Первинні перетворювачі (датчики інформаційних сигналів) також розміщують в певних точках.

Моделі вібраційних сигналів. Застосування $\mathrm{AR}, \mathrm{MA}, \mathrm{ARMA}$ моделей або їх модифікацій має значні переваги в порівнянні з іншими математичними моделями вібраційних сигналів вузлів електротехнічного обладнання, оскільки такі моделі дають можливість швидко відновити реалізації вібраційних сигналів, використовуючи параметри таких процесів. Такі моделі застосовуються не тільки в задачах діагностування технічного стану генераторів вітроустановок, а й, наприклад, для оцінки і прогнозування швидкості вітру [15, 17]. Однак, завдання відновлення ускладнюється, якщо вібраційний сигнал має відмінний від нормального розподіл.

У даній статті розглядається можливість використання лінійних процесів авторегресії $[1,2$, $16,17]$ для побудови алгоритмів моделювання вібросигналів обертових вузлів генераторів вітроустановок, що надзвичайно важливо для побудови випробувальних стендів, а також тренажерів для підготовки обслуговуючого персоналу вітроагрегатів [10, 11, 13].

Основною особливістю лінійних процесів авторегресії є можливість їх використання для опису негаусових випадкових сигналів, що мають безмежно-подільні розподіли. Розглянемо визначення таких процесів, а також їх властивості, більш детально.

Лінійні процеси авторегресії задаються наступним різницевим рівнянням

$$
\xi_{t}+\sum_{j=1}^{p} a_{j} \xi_{t-j}=\varsigma_{t}, \quad t \in Z,
$$

де $\left\{a_{j}, a_{j} \neq 0, j=\overline{1, p}\right\}$-параметри авторегресії; $Z$ - множина цілих чисел; $p$ - порядок авторегресії; $\left\{\zeta_{t}, t \in Z\right\}$ - деякий однорідний випадковий процес 3 дискретним часом і незалежними зна- 
ченнями, що має безмежно подільний закон розподілу $P\left\{\varsigma_{0}=0\right\}=1$. Цей процес часто називають породжуючим процесом для $\xi_{t}$.

Передбачається, що виконується співвідношення:

$$
\sum_{\tau=0}^{\infty} \varphi^{2}(\tau)<\infty, \quad \varphi(\tau) \equiv 0 \quad \text { при } \tau<0 .
$$

Логарифм одновимірної характеристичної функції для лінійного стаціонарного процесу 3 дискретним часом в канонічній формі А.М. Колмогорова визначають наступним чином

$$
\begin{gathered}
\ln f_{\xi}(u, t)=\ln f_{\xi}(u, 1)=i \\
=m_{\xi} u+\int_{-\infty}^{\infty}\left\{e^{i u x}-1-i u x\right\} \frac{d K_{\xi}(x)}{x^{2}},
\end{gathered}
$$

в якій параметр $m_{\xi}$ та спектральна функція стрибків А.М. Колмогорова $K_{\xi}(x)$ однозначно визначають характеристичну функцію [3, 4].

Логарифм характеристичної функції лінійного процесу с дискретним часом також записують і в такій формі

$$
\begin{gathered}
\ln f_{\xi}(u, t)=\ln f_{\xi}(u, t)=i m_{\zeta} u \sum_{\tau=-\infty}^{\infty} \phi(\tau)+ \\
+\sum_{\tau=-\infty}^{\infty} \int_{-\infty}^{\infty}\left(e^{i u x \phi(\tau)}-1-i u x \phi(\tau)\right) \frac{d K_{\zeta}(x)}{x^{2}}
\end{gathered}
$$

де параметри $m_{\varsigma}, K_{\zeta}(x)$ визначають характеристичну функцію породжующого процесу $\varsigma_{t}$, a $\varphi(\tau)$ - ядро лінійного випадкового процесу $\xi_{t}$. У співвідношеннях (3) і (4) $K_{\xi}(x), K_{\zeta}(x)$ - спадні обмежені функції такі, що $K_{\xi}(-\infty)=0$, $K_{\varsigma}(-\infty)=0$.

Параметри $m_{\xi}$ та $m_{\varsigma}$ і Пуасонівські спектри стрибків $K_{\xi}(x)$ и $K_{\zeta}(x)$ пов'язані між собою наступним чином (в припущенні, що процес $\xi_{t}$ стаціонарний, а $\varsigma_{t}$ - однорідний)

$$
\begin{gathered}
m_{\xi}=m_{\zeta} \sum_{\tau=0}^{\infty} \varphi(\tau), \\
K_{\xi}(x)=\int_{-\infty}^{\infty} R_{\varphi}(x, y) d K_{\zeta}(y),
\end{gathered}
$$

де $R_{\varphi}(x, y)$ - ядро перетворення.

Властивості ядра $\varphi(\tau)$ важливі для розв'язання оберненої задачі - визначення характеристичної функції породжуючого процесу $\varsigma_{t}$, якщо відома характеристична функція спостережуваного процесу $\xi_{t}$ і ядро спостережуваного процесу $\varphi(\tau)$. Деякі результати досліджень можливості розв'язання оберненої задачі для лінійних випадкових процесів 3 неперервним часом наведені в [10]. Для стаціонарних процесів авторегресії першого порядку AR (1), що мають Гамма i від'ємний біноміальний розподіл, характеристичні функції наведені в $[9,12,14]$.

Ядро перетворень $R_{\varphi}(x, y)$ для стаціонарних лінійних процесів 3 дискретним часом знаходять таким чином [16]

$$
R_{\varphi}(x, y)=\sum_{\tau=-\infty}^{\infty} \varphi^{2}(\tau) U[x-y \varphi(\tau)],
$$

де $\varphi(\tau)$ - ядро лінійного випадкового процесу 3 дискретним часом; $U[$.$] - функція Хевісайда.$

Ядро перетворення $R_{\varphi}(x, y)$ однозначно пов'язане з ядром лінійного випадкового процесу $\varphi(\tau)$. Інтеграл (6) $є$ інтеграл Лебега-Стілтьєса.

У даній роботі розглянуті особливості рішення для процесів оберненої задачі, тобто знаходження характеристичної функції породжуючого процесу, якщо спостерігається лінійний процес 3 дискретним часом і відома його характеристична функція. Для розв'язання оберненої задачі передбачається існування формули звернення для інтеграла (6).

Нехай лінійний процес авторегресії $\xi_{t}$ має Гамма-розподіл з одновимірною характеристичною функцією [5]

$$
f_{\xi}(u, t)=(1-i u \theta)^{-b} \quad \forall \quad t \in Z ; \quad \theta>0 ; \quad b>0 .
$$

Випадковий процес $\xi_{t} \in$ строго стаціонарним і для нього виконується ергодична теорема, тобто

1) $M\left|\xi_{t}\right|<\infty$,

2) $\frac{1}{m^{2}} \sum_{t=0}^{m} \sum_{n=0}^{m} r(t, n) \rightarrow 0$ при $m \rightarrow \infty$, $r(t, n)=\mathbf{M}\left[\left(\xi_{t}-\mathbf{M} \xi_{t}\right)\left(\xi_{n}-\mathbf{M} \xi_{n}\right)\right]-\quad$ кореляційна функція процесу $\xi_{t}$.

В цьому випадку пуасонівский спектр стрибків процесу у формулі А.М. Колмогорова визначається наступним чином

$$
\begin{gathered}
K_{\xi}(x)=b \int_{0}^{x} y \exp (-y / \theta) d y= \\
=\left\{\begin{array}{ll}
b \theta[\theta-(\theta+x) \exp (-x / \theta)] & x \geq 0 \\
0 & x<0
\end{array},\right.
\end{gathered}
$$

Звідси

$$
d K_{\xi}(x)=b x \exp (-x / \theta) d x, \quad x \geq 0 .
$$


Передбачається, що виконуються співвідношення $a_{1}, a_{2}<0, \quad a_{1}^{2}+4 a_{2}<0, \quad\left|a_{1}+a_{2}\right|<1$, $\left|a_{1}-a_{2}\right|<1, \quad-1<\left|a_{2}\right|<1, \quad\left|a_{1}\right|<1-a_{2}$.

Ядро перетворення $R_{\varphi}(x, y)$ згідно (7) визначається наступним чином

$$
R_{\phi}(x, y)= \begin{cases}\sum_{\tau=-\infty}^{\infty} \phi^{2}(\tau) & 0 \leq \phi(\tau) y<x \\ 0 & \phi(\tau) y>x ; \quad x<0 \quad y=0\end{cases}
$$

Існує зворотне ядро перетворення $R_{\varphi}^{-1}(x, y)$ згідно [14]

$$
R_{\phi}^{-1}(x, y)=\left\{\begin{array}{l}
{\left[\sum_{\tau=-\infty}^{\infty} \phi^{2}(\tau)\right]^{-1} 0 \leq \phi(\tau) y<x ;} \\
0 \quad \phi(\tau) y>x ; \quad x<0 ; y=0 .
\end{array}\right.
$$

Пуасонівський спектр стрибків породжуючого процесу $\varsigma_{t}$ для розглянутого випадку визначається наступним співвідношенням [5]

Звідси

$$
K_{\varsigma}(y)= \begin{cases}b\left|\sum_{\tau=-\infty}^{\infty} \varphi^{2}(\tau)\right|^{-1} \int_{0_{+}}^{y} x \exp (-x / \theta) d x, & y>0 \\ 0, & y=0 .\end{cases}
$$

Тоді

$$
K_{\varsigma}(y)= \begin{cases}b\left|\sum_{\tau=-\infty}^{\infty} \varphi^{2}(\tau)\right|^{-1}\{\theta-(\theta+y) \exp (-y / \theta)\}, & y>0 \\ 0, & y=0\end{cases}
$$

і логарифм характеристичної функції породжуючого процесу визначається наступним чином

$$
\ln f_{\varsigma}(u ; t)=|t| \ln f_{\varsigma}(u ; 1)=\left.\left.i \theta b|t|\right|_{\tau=-\infty} ^{\infty} \phi(\tau)\right|^{-1} u+b \theta|t|\left[\sum_{\tau=-\infty}^{\infty} \phi^{2}(\tau)\right] \int_{0}^{-1}\{\exp (i y u)-1-i u y\} \frac{\exp (-y / \theta)}{y} d y,
$$

$t \in Z$,де, $\theta>0, b>0, y>0,\left|a_{1}\right|<1-a_{2}$.

Після інтегрування отримаєм

$$
\ln f_{\varsigma}(u ; t)=|t| \ln f_{\varsigma}(u ; 1)=i \theta b|t|\left|\sum_{\tau=-\infty}^{\infty} \varphi(\tau)\right|^{-1} u+b \theta|t|\left[\sum_{\tau=-\infty}^{\infty} \varphi^{2}(\tau)\right]^{-1}[i u(1-\theta)-\ln (1-i u \theta)] . t \in Z,
$$

де $\theta>0, b>0, y>0$.

\section{Характеристична функція процесу вібра-} ції генераторів вітроустановок USW 56-100. Як приклад використання запропонованого підходу, розглянемо вібраційний сигнал обертового вузла підшипника кочення генератора вітроустановки USW 56-100 (рис.3.) з боку корпусу головного валу, встановленого на стенді для випробувань генераторів вітроустановок [2, 4]. Швидкість обертання головного валу 72 об / хв. Для досліджень вібраційних сигналів використовувався розроблений в ІЕД НАН України прототип системи діагностики генераторів вітроустановок, за допомогою якого були отримані оцінки параметрів авторегресії вібраційних сигналів, а також параметри їх розподілів [2].

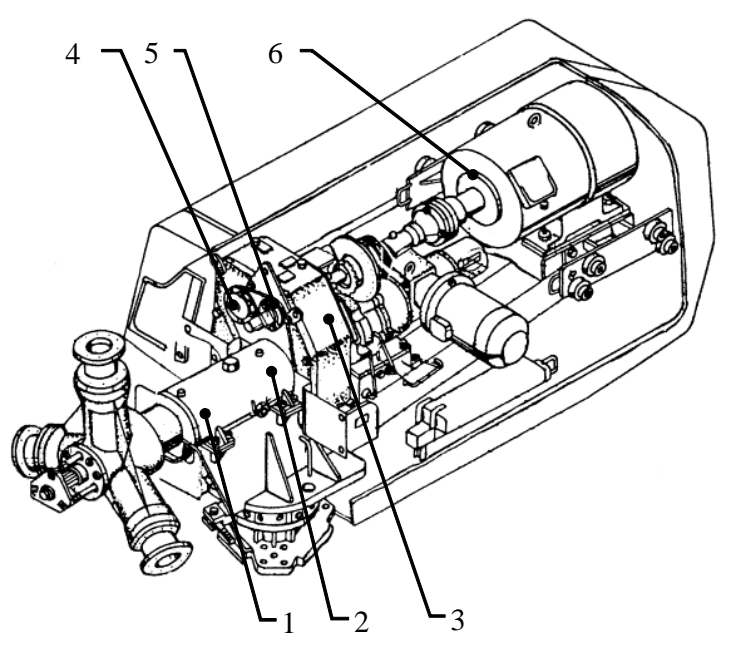

Рис. 3. Кріплення давачів для дослідження вібрацій генератора вітроустановки USW 56-100.

Fig. 3. Sensor mounts for USW 56-100 wind plant generator vibration research. 
У точці 1 вібраційний сигнал моделюється лінійним процесом авторегресії другого порядку 3 коефіцієнтами авторегресії $a_{1}=0.552$ i $a_{2}=-0.0036$, тобто

$$
\xi_{t}+0.552 \xi_{t-1}-0.0036 \xi_{t-2}=\varsigma_{t} .
$$

Процес $\xi_{t}$ має Гамма-розподіл з параметрами $\theta>0, b>0$, одновимірна характеристична функція, якого задана співвідношенням (8). В даному випадку ядро лінійного випадкового процесу авторегресії $\epsilon$ спадною позитивною функцією. Результати моделювання ядра представлені на рис. 4.

Методами математичного моделювання визначалися значення параметрів логарифма характеристичної функції (15) $\left[\sum_{\tau=0}^{n} \varphi(\tau)\right]^{-1}=0.452$ и $\left[\sum_{\tau=0}^{n} \varphi(\tau)^{2}\right]^{-1}=0.694$, при обсязі вибірки $\mathrm{n}=1000$. Тоді логарифм характеристичної функції породжуючого процесу $\varsigma_{t}$ в співвідношенні (15) визначається наступним чином

$$
\begin{aligned}
\ln f_{\varsigma}(u ; t)=|t| \ln f_{\varsigma}(u ; 1) & =0.452 i|t| \theta b u+0.694 \theta b|t| \int_{0}^{\infty}\{\exp (i y u)-1-i u y\} \frac{\exp (-y / \theta)}{y} d y= \\
& =b \theta|t|\{0.452 i u+0.694[i u(1-\theta)-\ln (1-i u \theta)]\} .
\end{aligned}
$$

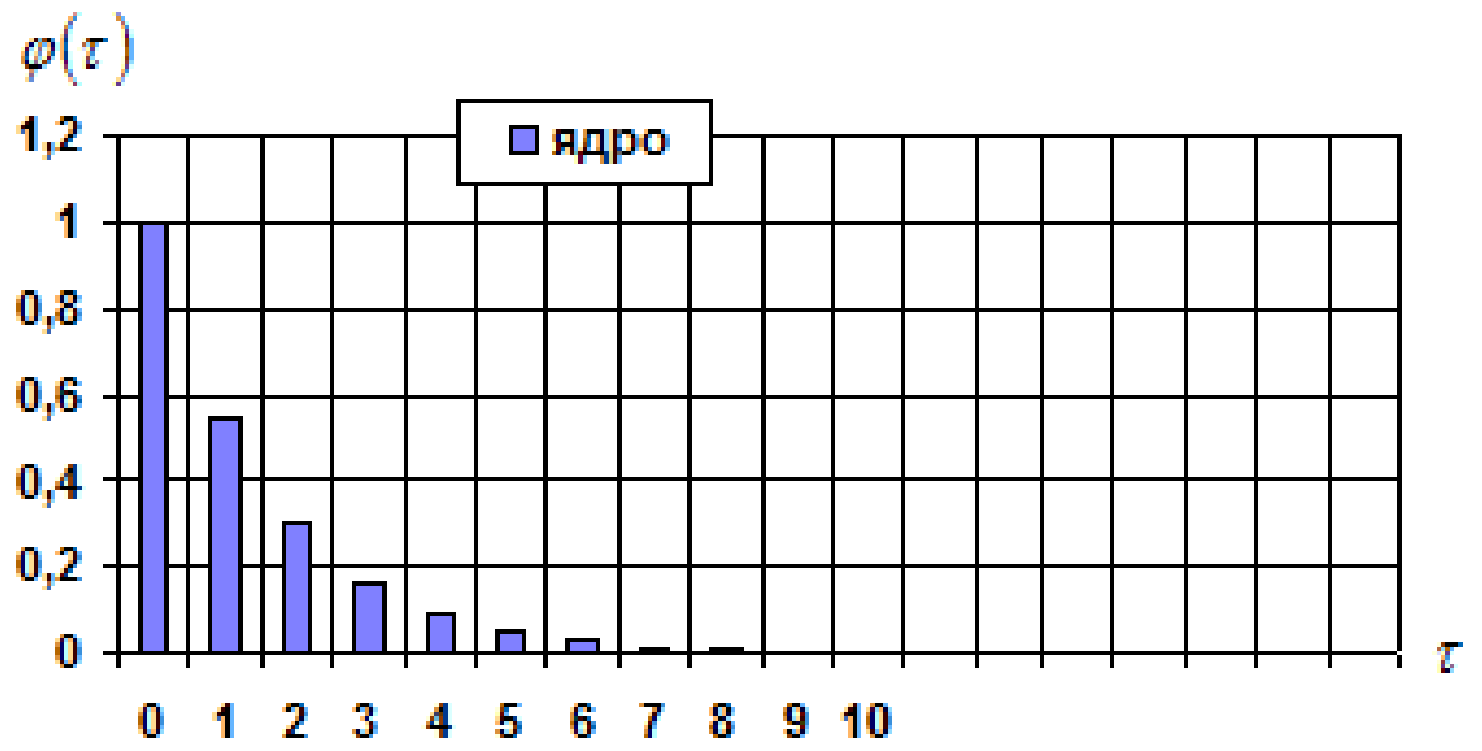

Рис. 4. Ядро лінійного процесу авторегресії $\mathbf{A R ( 2 ) ~ з ~ п а р а м е т р а м и ~} a_{1}=0.7688$ та $a_{2}=-0.0036$.

Fig. 4. Kernel of linear autoregressive process $\mathrm{AR}(2)$ with parameters $a_{1}=0.7688$ and $a_{2}=-0.0036$.

Однак, вирішити зворотну задачу для лінійних процесів авторегресії не завжди можна. У точці 2 вібраційний сигнал моделюється процесом авторегресії другого порядку з коефіцієнтами авторегресії $a_{1}=0.76875, a_{2}=-0.2813$, тобто

$$
\xi_{t}+0.76875 \xi_{t-1}-0.2813 \xi_{t-2}=\varsigma_{t},
$$




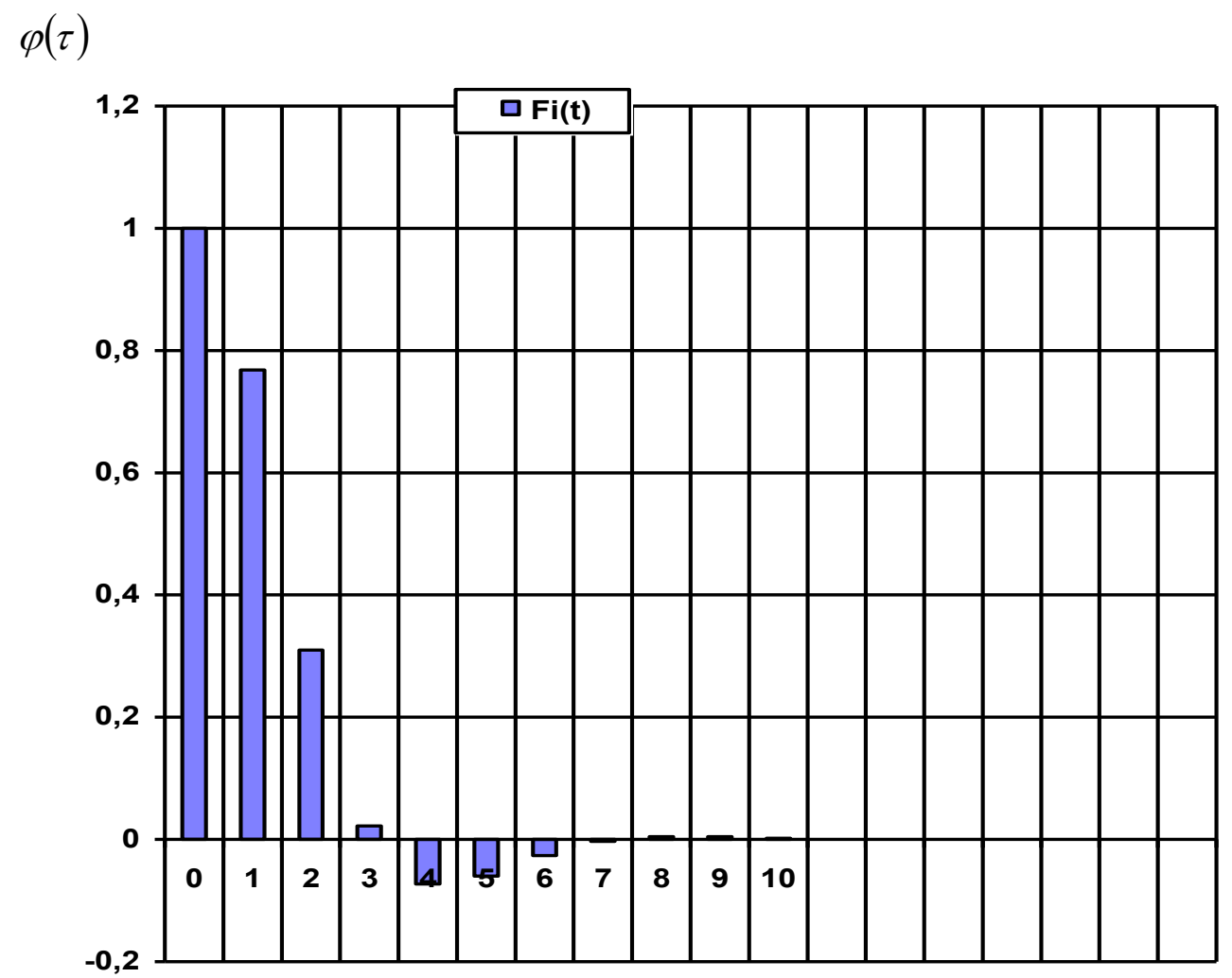

Рис. 5. Ядро лінійного процесу авторегресії AR(2) з параметрами $a_{1}=0.76875$ та $a_{2}=-0.2813$.

Fig. 5. Kernel of linear autoregressive process $\mathbf{A R}(2)$ with parameters $a_{1}=0.76875$ and $a_{2}=-0.2813$.

Ядро лінійного процесу авторегресії, яке показано на рис. 5, не є спадною позитивною функцією.

Тому рішення оберненої задачі для лінійного процесу авторегресії, що має таке ядро, не представляється можливим.

Якщо дослідження показали, що для лінійного процесу авторегресії, який має безмежноподільний закон розподілу, за допомогою якого моделюється вібраційний процес, вирішується зворотна задача, то з наперед заданою вірогідністю (з якою оцінюються параметри авторегресії і параметри розподілу процесу) можна, використовуючи відповідні датчики випадкових чисел 3 відомими характеристиками розподілу, відновити реалізацію вібраційного процесу для подальшого використання [8].

Висновок. Запропонований метод дозволяе побудувати характеристичну функцію породжуючих процесів для лінійних стаціонарних процесів авторегресії не тільки другого порядку, що мають Гамма-розподіл. Представлений метод доцільно використовувати і для знаходжень породжуючих процесів для лінійних процесів авторегресії вищих порядків, а також для вібраційних сигналів генераторів вітроустановок, що мають інші безмежно-подільні розподіли, попередньо дослідивши властивості ядра $\varphi(\tau)$, яке повинно бути спадною позитивною функцією. Як показано в наведених в статті експериментальних дослідженнях, це не завжди можливо.

Стаття підготовлена в рамках виконання наукових проектів цільових програм Національної академії наук України «Ресурс-2», «Нова енергетика», «Підтримка розвитку пріоритетних напрямів наукових досліджень» (КПКВК 6541230).

1. Зварич В.Н., Марченко Б.Г. Линейные процессы авторегрессии в задачах вибродиагностики узлов электрических машин. Техническая диагностика и неразрушающий контроль. 1996. №1. С. 45-54.

2. Зварич В.Н. Применение методов авторегрессии для построения систем вибродиагностики ветроагрегатов. Відновлювана енергетика. 2005. №1. С. 49-54.

3. Зварич В.Н., Марченко Б.Г. Метод нахождения характеристических функций порождающих процессов для линейных процессов авторегрессии. Изв. Вузов Радиоэлектроника. 1999. т. 42. № 7. С.64-71.

4. Зварич В.Н. Использование решений обратной задачи линейных процессов авторегрессии для моделирования вибрационных сигналов узлов электротехнического оборудования. Технічна електродинаміка. 2016. № 2. С. 83-89.

5. Зварич В.Н., Марченко Б.Г. Характеристическая функция порождающего процесса в модели стационарного линейного AR гамма процесса. Известия ВУЗов «Радиоэлектроника». 2002. Т. 45. № 8. C. 12-18. ISSN 0021-3470.

6. Красильников А.И. Модели шумовых сигналов в системах диагностики теплоэнергетического оборудования. Киев. Полиграф-сервис. 2014. 112 с. 
7. Марченко Б.Г., Мыслович М.В. Вибродиагностика подшипниковых узлов электрических машин. Киев. Наукова думка. 1992. 196 с.

8. Марченко Б.Г., Зварич В.Н., Бедный Н.С. Линейные случайные процессы в некоторых задачах моделирования информационных сигналов. Электронное моделирование. 2001. T. 23. № 1. C. 62-69.

9. Alliot $P$. Some theoretical results on Markov-switching autoregressive models with gamma innovations. C.R. Acad. Sci. Paris. 2006. Ser. I 343. Pp. 271-274.

10. Bayar T. Putting Wind to the Test. Power Engineering International. 2015. No. 12. Pp. 16-18.

11. Hoelf $D$. When Virtual meets Reality. Power Engineering International. 2016. No. 9. Pp. 26-27.

12. Lawrance A.J. The Innovation Distributions for Gamm Distributed Autoregressive Process.Scandinavian Journal of Statistics. Theory and Applications. 1982. Vol. 9. Pp. 234-236.

13. Manning $L$. Bearing up to turbine testing. Power Engineering International. - 2014. - No 2. pp. 32-34.

14. McKenzie Ed. Innovation Distributions for Gamma and Negative Binomial Autoregressions. Scandinavian Journal of Statistics. Theory and Applications. 1987. Vol. 14. Pp. 79-85.

15. Torres G.L., Garia A., Blas M.D., Francisco A.D. Forecast of hourly average wind speed with ARMA models in Navarre (Spain). Solar energy. Vol.79. 2005. Pp. 65-77.

16. Zvaritch V., Glazkova E. Application of Linear AR and ARMA Processes for Simulation of Power Equipment Diagnostic System Information Signals. Proceedings 201516 th International Conference on Computational problems of Electrical Engineering (CPEE). Lviv. Ukraine. 2015. Pp. 259-261.

17. Zvaritch V., Glazkova E. Some Singularities of Kernels of Linear AR and ARMA Processes and Their Applications to Simulation of Information Signals. Computational Problems of Electrical Engineering. 2015. Vol. 5. No. 1. Pp. 71-74.

\section{REFERENCES}

1. Zvaritch V.N., Marchenko B.G. Lineynyye protsessy avtoregressii $\mathrm{v}$ zadachakh vibrodiagnostiki uzlov elektricheskikh mashin. [Linear processes of autoregression in problems of vibrodiagnostics of sections of electric drivers]. Technical Diagnostics and Nondestructive Testing. 1996. No. 1. Pp.45-54. [in Russian].

2. Zvarich V.N. Primeneniye metodov avtoregressii dlya postroyeniya sistem vibrodiagnostiki vetroagregatov. [Autoregression methods application for development of wind generators diagnostic systems]. Vidnovluvana energetika. 2005. No. 1. Pp. 49-54. [in Russian].

3. Zvarich V.N., Marchenko B.G. Metod nakhozhdeniya kharakteristicheskikh funktsiy porozhdayushchikh protsessov dlya lineynykh protsessov avtoregressii. [Method of finding of generating processes characteristic functions of autoregression linear processes]. Radioelectronics and Communication Systems. 1999. v. 42. No. 7. Pp. 64-71. [in Russian].

4. Zvarich V.N. Ispolzovaniye resheniy obratnoy zadachi lineynykh protsessov avtoregressii dlya modelirovaniya vibratsionnykh signalov uzlov elektrotekhnicheskogo oborudovaniya [Application of invers problem solutions of the linear autoregressive processes for power equipment vibromonitoring]. Tekhnichna Elektrodynamika. 2016. No. 2. Pp. 83-89. [in Russian].

5. Zarich V.N., Marchenko B.G. Kharakteristicheskaya funktsiya porozhdayushchego protsessa $\mathrm{v}$ modeli statsionarnogo lineynogo AR gamma protsessa. [Generating process characteristic function in the model of stationary linear AR-gamma process]. University News "Electronics". 2002. v. 45. No. 8. Pp. 1218. ISSN 0021-3470. [in Russian].

6. Krasilnikov A.I. Modeli shumovykh signalov v sistemakh diagnostiki teploenergeticheskogo oborudovaniya. [Mod- els of noise type signals at the diagnostic systems of heat power engineering equipment]. Kiev. Polygraph-service. 2014. 112 p. [in Russian].

7. Marchenko B.G., Myslovich M.V. Vibrodiagnostika podshipnikovykh uzlov elektricheskikh mashin. [Vibration Diagnosis of rolling bearings of electric driver parts]. M. Kiev. Naukova dumka. 1992. 196 p. [in Russian]

8. Marchenko B.G., Zvarich V.N., Bedny N.S. Lineinye sluchainye protsessy $\mathrm{v}$ nekotorykh zadachakh modelirovaniya informatsionnykh signalov. [Linear random processes in the some problems of information signals simulation]. Electronic modeling. [Elektronnoe modelirovanie]. 2001. v. 23. No. 1. Pp. 62-69. [in Russian]

9. 13. Alliot P. Some theoretical results on Markovswitching autoregressive models with gamma innovations. C.R. Acad. Sci. Paris. 2006. Ser. I 343. Pp. 271-274. [in English].

10. Bayar T. Putting Wind to the Test. Power Engineering International. 2015. No. 12. Pp. 16-18. [in English].

11. 9. Hoelf D. When Virtual meets Reality. Power Engineering International. 2016. No. 9. Pp. 26-27. [in English].

12. 12. Lawrance A.J. The Innovation Distributions for Gamma Distributed Autoregressive Process.Scandinavian Journal of Statistics. Theory and Applications. 1982. Vol. 9. Pp. 234236. [in English].

13. Manning $L$. Bearing up to turbine testing. Power Engineering International. - 2014. - No 2. pp. 32-34. [in English].

14. 12. McKenzie Ed. Innovation Distributions for Gamma and Negative Binomial Autoregressions. Scandinavian Journal of Statistics. Theory and Applications. 1987. Vol. 14. Pp. 79-85. [in English]

15. 8. Torres G.L., Garia A., Blas M.D., Francisco A.D. Forecast of hourly average wind speed with ARMA models in Navarre (Spain). Solar energy. Vol.79. 2005. Pp. 65-77. [in English]

16. Zvaritch V., Glazkova E. Application of Linear AR and ARMA Processes for Simulation of Power Equipment Diagnostic System Information Signals. Proceedings 201516 th International Conference on Computational problems of Electrical Engineering (CPEE). Lviv. Ukraine. 2015. Pp. 259-261. [in English].

17. Zvaritch V., Glazkova E. Some Singularities of Kernels of Linear AR and ARMA Processes and Their Applications to Simulation of Information Signals. Computational Problems of Electrical Engineering. 2015. Vol. 5. No. 1. Pp. 71-74. [in English].

\section{ПРИМЕНЕНИЕ РЕШЕНИЙ ОБРАТНОЙ ЗАДАЧИ ЛИНЕЙНЫХ ПРОЦЕСОВ АВТОРЕГРЕССИИ С ЦЕЛЬЮ ПОСТРОЕНИЯ СИСТЕМ ВИБРОДИАГНОСТИКИ УЗЛОВ ГЕНЕРАТОРОВ ВЕТРОУСТАНОВОК}

\section{В.Н. Зварич, докт. техн. наук}

Институт электродинамики НАН Украины, 03680, г. Киев, пр-т Победы 56

Институт возобновляемой энергетики НАН Украины, 02094, г. Киев, ул. Гната Хаткевича, 20A

В работе рассмотрены некоторые методы диагностирования технического состояния энергетического оборудования. Приведены сравнения различных методов вибродиагности$\kappa и$, которые могут быть использованы при диагностировании технического состояния генераторов ветроустановок. Рассмотрено использование линейных случайных процессов для построения систем диагностики генераторов ветроустановок. Представлен метод нахождения характеристической функиии порождающего прочесса для линейного проиесса авторегрессии второго порядка $A R(2)$, что имеет 
Гамма-распределение. Свойства пуассоновский спектров прыжсков используются для решения этой проблемы. Решение такой задачи, которую часто называют обратной базируется на свойства характеристической функции стационарного линейного случайного процесса авторегресcuи $A R(2), \quad \xi_{t}+a_{1} \xi_{t-1}+a_{2} \xi_{t-2}=\varsigma_{t}, \quad t \in Z$, где $\left\{a_{1}, a_{2} \neq 0\right\}$ параметры авторегресии; $\mathrm{Z}=\{\ldots,-1,0,1, \ldots\}$ множество ичельхх чисел; $\left\{\zeta_{t}, t \in Z\right\}$ случайный прочесс с дискретным временем и независимыми значениями, имеет бесконечно делимый закон распределения, который часто называют порождаюшим процессом. Иногда такую задачу называют обратной задачей. В статье отмечается что одномерный логарифм характеристической функиии линейного стационарного прочесса авторегрессии можно задать одномерной характеристической функиией в каноническом представлении Колмогорова

$\ln f_{\xi}(u, t)=\ln f_{\xi}(u, 1)=i m_{\xi} u+\int_{-\infty}^{\infty}\left\{e^{i u x}-1-i u x\right\} \frac{d K_{\xi}(x)}{x^{2}}, \quad$ де napaметр $m_{\xi}$ и спектральная функиия прыжков $K_{\xi}(x)$ однозначно определяют характеристическую функиию. Логарифм характеристической функции линейного стационарного процесса авторегрессии может быть также записана в следующей форме $\ln f_{\xi}(u, t)=\ln f_{\xi}(u, t)=$

$=\operatorname{im}_{\zeta} u \sum_{\tau=-\infty}^{\infty} \phi(\tau)+\sum_{\tau=-\infty}^{\infty} \int_{-\infty}^{\infty}\left(e^{i u x \phi(\tau)}-1-i u x \phi(\tau)\right) \frac{d K_{\zeta}(x)}{x^{2}}$ гдe napaмem- ры $m_{\varsigma} u K_{\zeta}(x)$ определяют характеристическую функиию порождающего прочесса $\varsigma_{t} a \phi(\tau)$ является ядром линейного случайного прочесса $\xi_{t}$. Параметры $m_{\xi} u m_{\varsigma}$, и пуассоновский спектра прыжков $K_{\xi}(x)$ взаимосвязаны следующим образом $m_{\xi}=m_{\zeta} \sum_{\tau=0}^{\infty} \phi(\tau), \quad K_{\xi}(x)=\int_{-\infty}^{\infty} R_{\phi}(x, y) d K_{\zeta}(y)$. $R_{\phi}(x, y)$ является ядром преобразования которое является инвариантным к порождающему $\varsigma_{t}$ и определяется с помощуью коэффициентов $\left\{a_{1}, a_{2} \neq 0\right\}$. Свойства $R_{\phi}(x, y)$ используются для решения обратной задачи. Показан пример нахождения пуассоновский спектров прыжков и характеристической функиии для линейного процесса авто регрессии второго порядка, что имеет Гаммараспределение Метод может быть использован для решения обратной задачи для авторегрессионных процессов других классов. Показано использование полученных результатов для моделирования вибрационных сигналов генератора ветроустановки. Библ. 17, рис. 5

Ключевые слова: линейный процесс авторегрессии, характеристическая функция, ядро преобразования, порождающий проиесс, безгранично делимый закон распределения, Гаммараспределение, вибродиагностика генераторов ветроустановок.

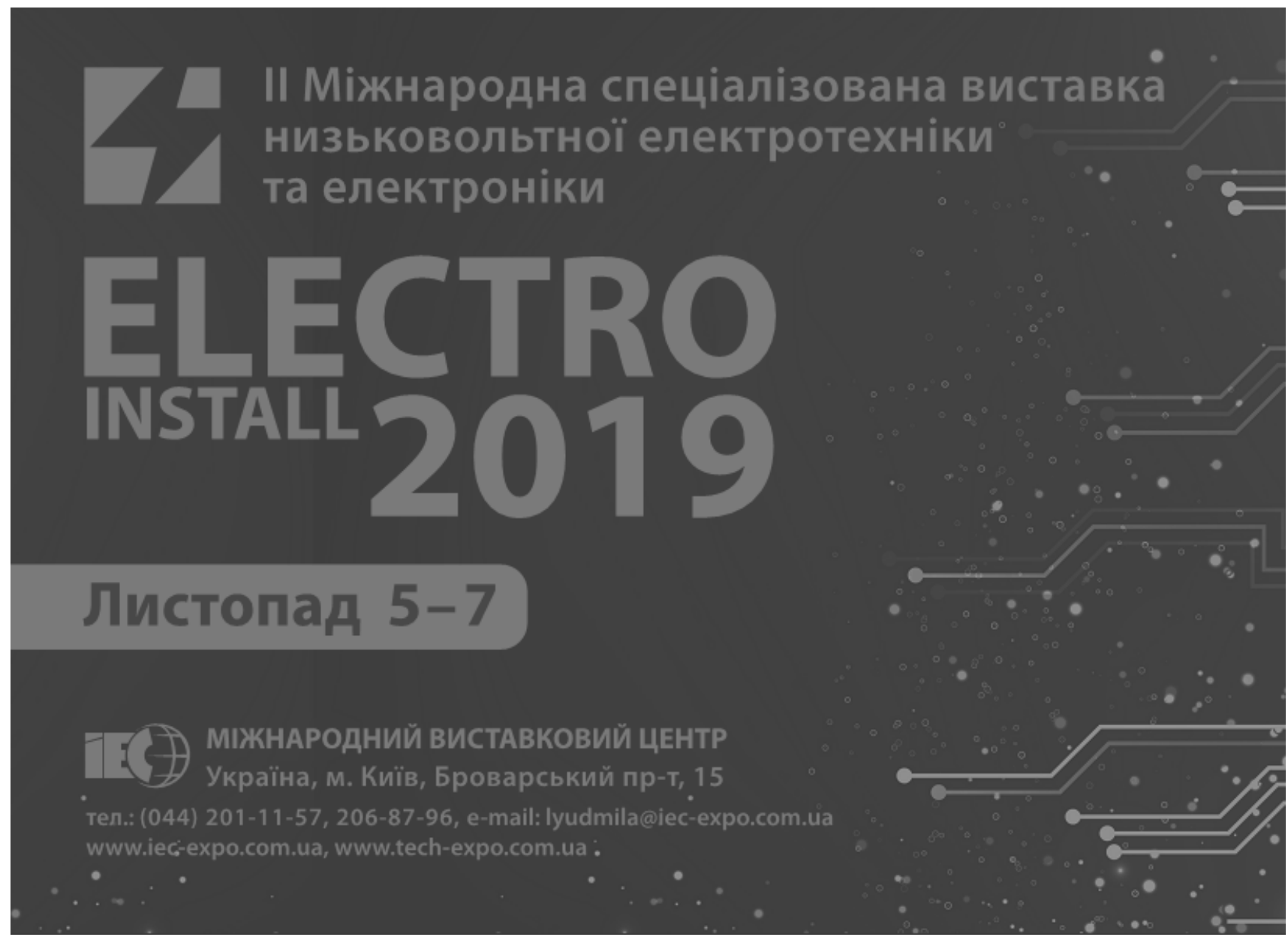

